\title{
Fragile X chromosome: clinical and cytogenetic studies on cases from seven families
}

\author{
A MCDERMOTT*, RUTH WALTERS $\dagger$, R T HOWELL*, AND \\ ANNE GARDNER* \\ From*the South Western Regional Cytogenetics Centre, Southmead Hospital, Bristol, and \\ $\dagger$ Hanham Hall Hospital, Hanham, Bristol.
}

SUMMARY Results of detailed clinical and cytogenetic studies on 13 mentally retarded males and two heterozygous females (one normal and one retarded) are reported. Reference is made to technical modifications to enhance the incidence of expression of the fragile $X$. The addition of excess methionine to the fibroblast cultures (final concentration of $115 \mathrm{mg} / \mathrm{l}$ medium TC 199) was found to be particularly valuable, increasing the incidence of expression up to four-fold, and enabling the demonstration of the fragile $\mathrm{X}$ in fibroblasts when it could not be demonstrated in blood cultures in at least one case. Studies on replication patterns of the $\mathrm{X}$ chromosomes in the two heterozygous females showed that the fragile $X$ chromosome was genetically active in a significantly greater proportion of cells $(74 \%)$ in the mentally retarded female, whereas the normal $\mathrm{X}$ was active in a similar proportion $(72 \%)$ in the carrier with normal intelligence.

An excess of males in mentally retarded populations has long been recognised ${ }^{1}$ and it is generally accepted that a number of $X$ linked disorders accounts for the major proportion of this excess. ${ }^{2-5}$ The eponyms 'Martin-Bell syndrome' 6 and 'Renpenning syndrome'7 have been ascribed to many cases of nonspecific familial X linked mental retardation. More recently, the recognition that the condition may be accompanied by macro-orchidism in some families, ${ }^{8}$ and the discovery that some cases are associated with a distinctive chromosomal aberration, the 'fragile X', have offered improved prospects for rationalising the differential diagnosis.

Credit for the first report of the fragile site as a marker X chromosome goes to Lubs ${ }^{9}$ and to Harvey et $a l^{10}$ for the lead in recognising its potential significance. Sutherland ${ }^{11}$ established that the recipe of the culture medium was all important in demonstrating the aberration and many cases have now been re-evaluated. Richards et al $^{12}$ found macroorchidism and the fragile $\mathrm{X}$ site in some members of the Martin-Bell family but members of the family described by Renpenning showed neither characteristic. ${ }^{13}$ It appears, therefore, that the Renpenning syndrome of $X$ linked mental retardation is a separate distinct entity.

Received for publication 5 November 1982. Accepted for pub!ication 8 November 1982.
Despite many studies, the fragile $\mathrm{X}$ syndrome remains an enigma and many aspects require further clarification. Phenotypic features are subtle and not invariably present, but more precise delineation of clinical signs would help to identify and select patients for the detailed chromosome studies required for diagnosis. The manifestation of the fragile site in only a proportion of cells, so netimes very small, underlines the continuing need to develop technical modifications which will enhance the expression of the aberration in cultures, particularly fibroblast and amniotic fluid cell cultures, so that antenatal diagnosis of this condition can be offered with greater confidence. There is also a need for more data on the behaviour of the fragile $X$ in heterozygous females, particularly on the $\mathrm{X}$ inactivation pattern in cultures and its correlation with mental capacity. This may eventually become an important factor in the prediction of disease in antenatally identified females.

This paper presents data relating to each of these aspects, derived from clinical and cytogenetic studies of 13 retarded males and two hetcrozygous females (one normal and one retarded) from seven families carrying the fragile $\mathrm{X}$ chromosome. One family was previously classified as Renpenning syndrome and one family as Rubinstein-Taybi syndrome. ${ }^{1415}$ 
TABLE 1 Clinical data.

\begin{tabular}{|c|c|c|c|c|c|c|c|c|c|c|c|c|c|c|}
\hline & $E A$ & $B A$ & $I H$ & $H H$ & $W H$ & $G W$ & $E \boldsymbol{W}$ & $W W$ & $E M$ & $E R$ & $K R$ & $B R$ & $G G$ & $G N$ \\
\hline Age (years) & 41 & 35 & 60 & 53 & 45 & Died at 63 & 68 & 59 & 46 & 46 & 44 & 39 & 23 & 35 \\
\hline IQ & 15 & 20 & 35 & 43 & 15 & 23 & 23 & 21 & 23 & 29 & 27 & 27 & 24 & 29 \\
\hline Height (cm) & 173 & 165 & 163 & 164 & 170 & 159 & 160 & 161 & 155 & 147 & 153 & 167 & 167 & 177 \\
\hline Weight (kg) & 56 & 69 & 54 & 57 & 65 & 61.4 & 61 & $52 \cdot 1$ & 49 & 54 & 55 & 57 & 64 & $72 \cdot 5$ \\
\hline Skull OFC $(\mathrm{cm})$ & 55 & 58 & $58 \cdot 5$ & 56 & 55 & 55 & 57 & 57 & $55 \cdot 5$ & 53 & 56 & 56 & $55 \cdot 5$ & 56 \\
\hline \multicolumn{15}{|c|}{ Testicular volume $(\mathrm{ml})^{*}$} \\
\hline Right & 97 & 70 & 26 & 69 & + & Abnormally & 46 & 59 & 74 & Normal female & 32 & 85 & 32 & 69 \\
\hline Left & 88 & 61 & 35 & 57 & 50 & large & 43 & 35 & 50 & genitals & $38 \cdot 5$ & 72 & 42 & 63 \\
\hline Sexual activity & - & 一 & + & + & - & + & - & - & + & Menstruates & - & - & - & + \\
\hline
\end{tabular}

*Volume of testis at 19-20 years in general population is $18 \cdot 6 \pm 4.0 \mathrm{ml}$.

+Operation on testicle at the age of 44 .

\section{Clinical studies}

The study began when a member of family A (III.8) sought genetic counselling as he was the father of a mentally retarded infant with Down's syndrome (IV.7). At that time III.20 was being investigated elsewhere (AH III.17 in reference ${ }^{16}$ ). All the adult male subjects have been in residential institutions for the mentally subnormal for many years. Their IQs have been assessed at regular intervals on the Terman Merrill scale and have shown no significant change. All were studied clinically, radiologically, and by laboratory investigation. Quantitative data for the adults are given in table 1 ; the testicular volumes were calculated from the length (L) and width (W) using the formula for an ellipsoid: $\pi / 6 \times \mathrm{L} \times \mathrm{W}^{2} .^{17}$ Tests for blood count, red cell folate, WR, serum electrolytes, urea, proteins, calcium, alkaline phosphatase, lipids, thyroid function, and urine chromatography for amino-acids, sugars, and mucopolysaccharides were normal. Serum testosterone and gonadotrophins were investigated in seven cases with normal results except where stated.

FAMILY A (FIG 1)

Probands EA and BA are brothers. Their sister, SP, their brother, DA, and their nephew, AP, were also investigated for the presence of the fragile $X(\mathrm{q} 27)$.

$E A(I I I .1, f i g)$ is a quiet man who rocks and bites his hands when upset. He is only able to make a few speech sounds and seldom vocalises. He has brown eyes with bilateral astigmatism ( 2 dioptres), a high palate, asymmetry of the skull, and a shield-shaped thorax with dorsal scoliosis. The hands and fingers are long (metacarpal index $8 \cdot 4$, normal upper limit 7.9) with dystrophic interphalangeal joints. He has

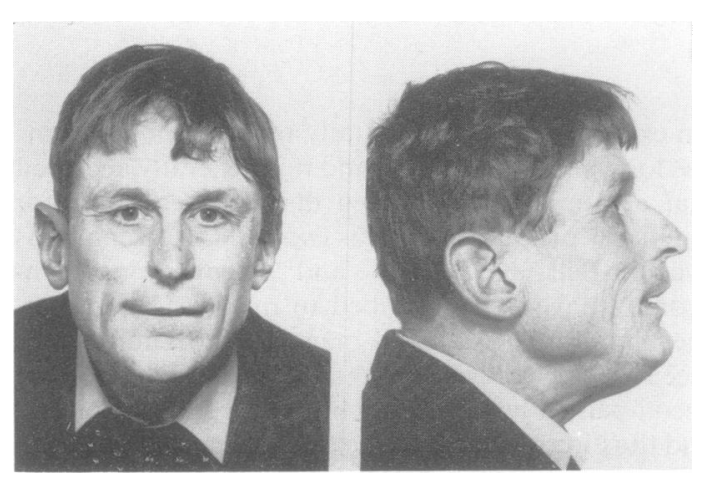

FIG 2 Patient $E A$.

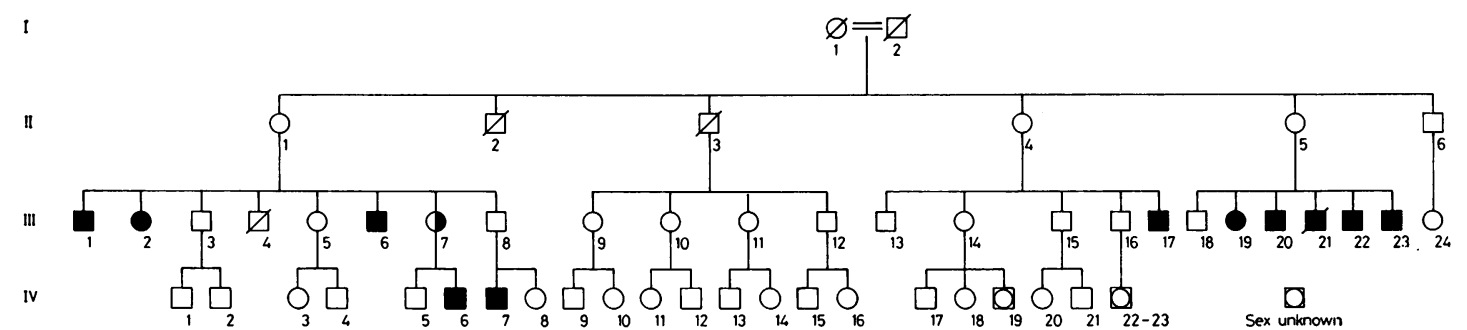

FIG 1 Pedigree of family A. II.1. Born 1915. Vitiligo. II.4. Pernicious anaemia. III.1. EA born 1940. Retarded. Has fra (X). III.2. Born 1941. Mildly retarded. III.4. Born 1942. Died aged 2 months of congenital hypertrophic pyloric stenosis. III.6. BA born 1946. Retarded. Has fra (X). III.7. Normal IQ. Heterozygous for fra (X). III.8. Normal IQ. No fra(X). III.17. Born 1958. Retarded. III.18-23 Family H. ${ }^{22}$ IV.6. Born 1977. Retarded. IV.7. Born 1979. Retarded. Down's syndrome (trisomy 21). Fragile X demonstrated in III.1, 6, 7, 17, 19, 20, 22, 23, and IV.6. 


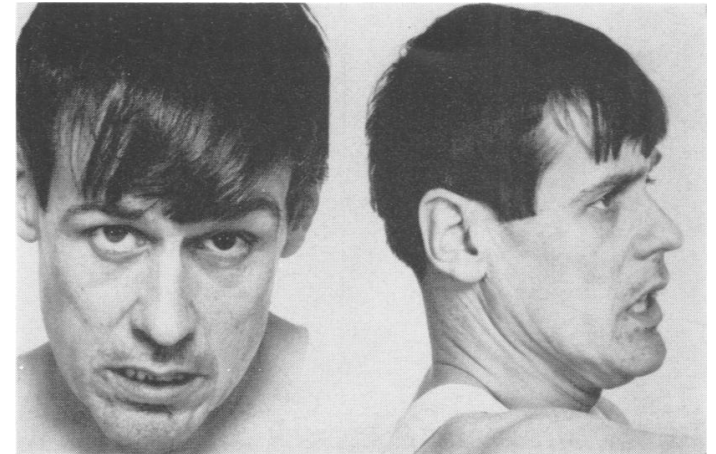

FIG 3 Patient $B A$.

inguinal creases and the skin is fine and soft in texture with sparse beard and bodily hair. At the age of 28 a left spermatocele was aspirated.

$B A$ (III.6, fig 3) is active, rocks, and is very anxious and apprehensive. He speaks in single words and short phrases in a quiet voice with good articulation and some echolalia. He has brown eyes, dorsolumbar scoliosis, and asymmetry of the legs, the right being larger and longer than the left. He has broad digits and clinodactyly of the left fourth and fifth fingers and right fifth finger.

$S P$ (III.7) is a normal female, heterozygous for the fragile $X$.

$A P$ (IV.6, fig 4) is aged 4 years 8 months. His height is $108 \mathrm{~cm}$, weight $19.8 \mathrm{~kg}$, and OFC $53 \mathrm{~cm}$ (80th centile). He had a normal birth after 43 weeks' gestation, birth weight $3.97 \mathrm{~kg}$.

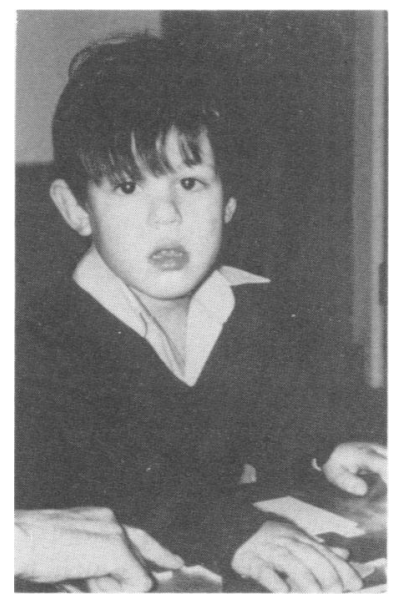

FIG 4 Patient $A P$.
Development was slow: he sat alone at 13 months, walked at 20 months, and had only one or two words of speech by 24 months. At 50 months his mental age on the Griffiths developmental scale was 28 months (locomotor scale and personal scale 30 months; hearing and speech scale and eye/hand co-ordination scale 28 months; and performance scale 24 months). $\mathrm{He}$ is very restless and easily distracted and is apprehensive, dislikes change, and displays rocking and hand and finger posturing. He is preoccupied with water play and hand wiping. The speech has some individual clear words with much jargon. He has brown eyes with epicanthic folds, facial asymmetry, hypoplasia of the maxilla, hyperplasia of the mandible, large ears, the right having architectural anomalies of the pinna, broad digits, and clinodactyly of the right fifth finger. The genitalia are of normal size.

FAMILY H (FIG 5)

Probands $\mathrm{IH}$ and $\mathrm{HH}$ are brothers. WH is their nephew, the illegitimate son of their sister who is described as being 'of poor mentality' in their records.

IH (II.6, fig 6) is a cheerful co-operative man, working in the hospital laundry and garden. He has an abrupt deep voice with a vocabulary at the 8-year-old standard. He has facial asymmetry with an antimongoloid slant of the left eye and heterochromia of the irises. There is increased pigmentation of the areola and mottled pigmentation, maximal over the abdomen, and keratin cysts over his back. He has neck webbing, dorsal kyphosis, broad digits, long toes with the third toes curved and overlapping, bilateral varicose veins, and haemorrhoids. Sub-maxillary duct calculi were removed at the age of 41 . Serum FSH was raised.

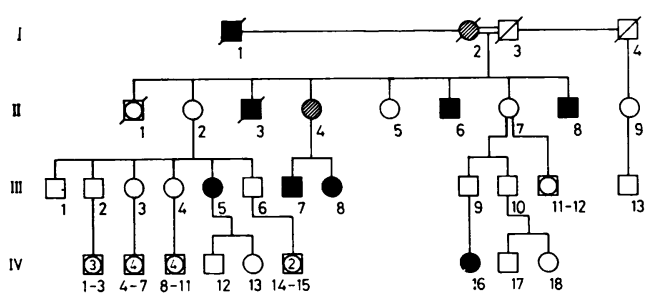

FIG 5 Pedigree of family H. I.I. 'Mentally handicapped'. I.2. Born 1883. 'Simple'. II.3. Died aged 17. Retarded. II.4. Born 1914. 'Poor mentality'. II.6. IH born 1921. Retarded. Fra (X). II.8. HH born 1928. Retarded. Fra(X). III.5. Mildly retarded. III.7. WH born 1936. Retarded. Fra (X). III.8. Retarded. IQ 69. IV.16. Attends special school. Fragile X demonstrated in II.6, II.8, and III.7. 


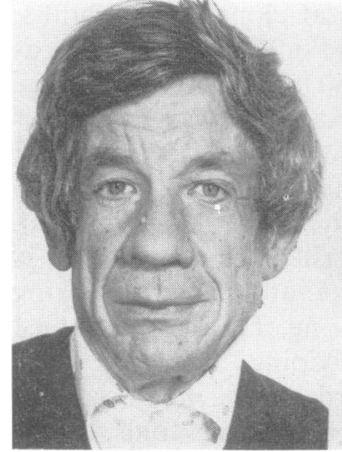

FIG 6 Patient IH.

$H H(I I .8, f i g)$ is independent, solitary, and eventempered, working as a gardener. Speech and articulation are normal with vocabulary at the 8 -year-old standard. He has heterochromia of the irises with a right convergent squint. The skin shows small patches of pale café-au-lait pigmentation, maximal over the abdomen and on the neck. The chest shows marked asymmetry with the left shoulder higher than the right. There was neck webbing on the left, pectus excavatum, prominent fourth costochondral junctions, and dorsal kyphoscoliosis, lumbar lordosis, broad digits, and pes planus.

WH (III.7, fig 8) is quiet, solitary, and anxious and his speech is disjointed, syllabic, and perseverative. $\mathrm{He}$ has heterochromia of the irises, ptosis on the left, pectus excavatum, prominent fourth costochondral junctions, broad digits, and curved overlapping fourth toes. At the age of 42 he underwent thoracotomy and partial right lobectomy for lung abscess and at the age of 44 underwent an operation for a right epididymal cyst and testicular biopsy, which showed normal histology and spermatogenesis. Serum FSH was raised.

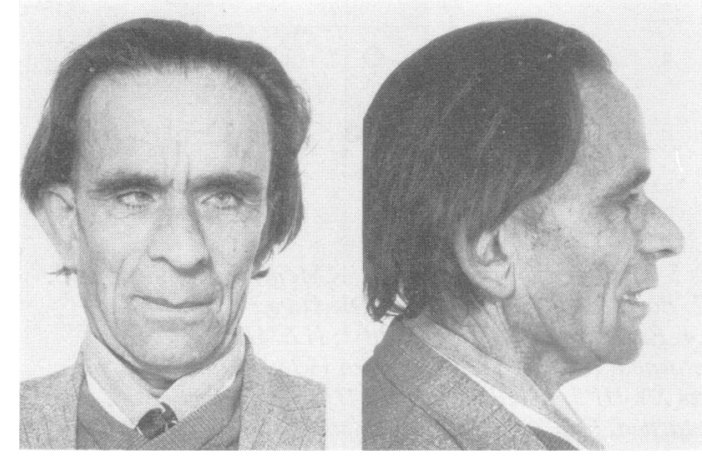

FIG 7 Patient $\mathrm{HH}$.

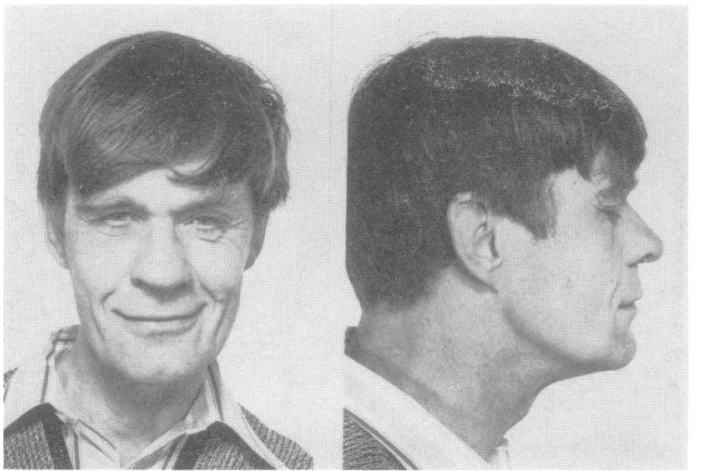

FIG 8 Patient $W H$.

FAMILY W (FIG 9)

This family was formerly classified as Renpenning syndrome. Probands EW and WW are brothers. GW died at the age of 63 in 1975 from carcinoma of the rectum.

$E W(I I .7, f i g 10)$ is sociable but easily upset, becoming emotional and aggressive. He talks continuously in simple repetitive sentences with defective articulation. He has blue eyes with arcus senilis, his chest is shield-shaped and shows dorsal kyphosis, and he has pectus excavatum, gynaecomastia, grooved sagittal suture, long digits, and bilateral varicose veins. EEG showed low amplitude complex activity covering a wide range of theta, alpha, and beta frequencies. With eyes closed low amplitude $10 \mathrm{c} / \mathrm{s}$ alpha frequencies were noted occipitally and there was a mild excess of slower components.

$W W(I I .9$, fig 11$)$ is cheerful, sociable, and restless. His speech is distinctly unusual, rapid, and repetitive, including jargon and coprolalia, with meaningful phrases interspersed and clear articulation. There is heterochromia of irises and xanthoma of the right upper eyelid. The chest is barrel-shaped with kyphosis and he has long digits, right Dupuytren's contracture, and pes planus. The skin is fine in texture with dermatitis over the trunk. EEG showed low amplitude (up to $15 \mu \mathrm{V}$ ) complex slow activity of mainly theta frequencies.

$G W(I I .5)$ died before fra(X) investigations. He had facial features closely resembling those of his brother, EW, and was overactive and restless with monosyllabic speech. In middle age he developed episodes of psychosis, treated with phenothiazines, and became withdrawn and doubly incontinent. At times he appeared to be hallucinating, holding his hands over his ears and becoming very agitated. 


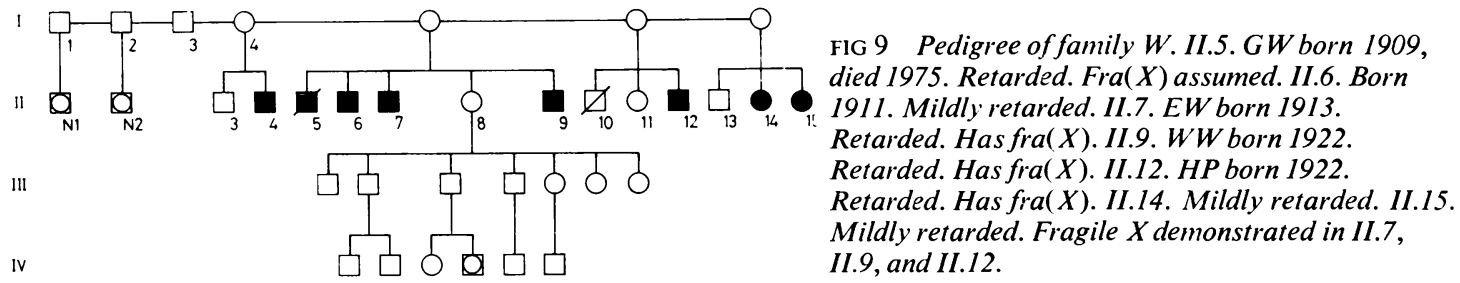

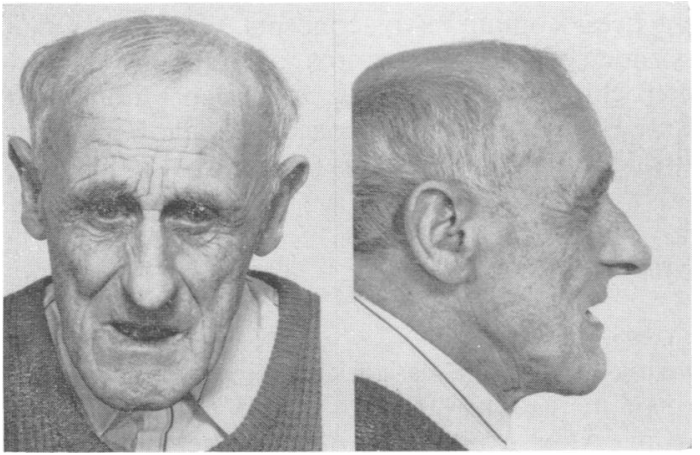

FIG 10 Patient EW.

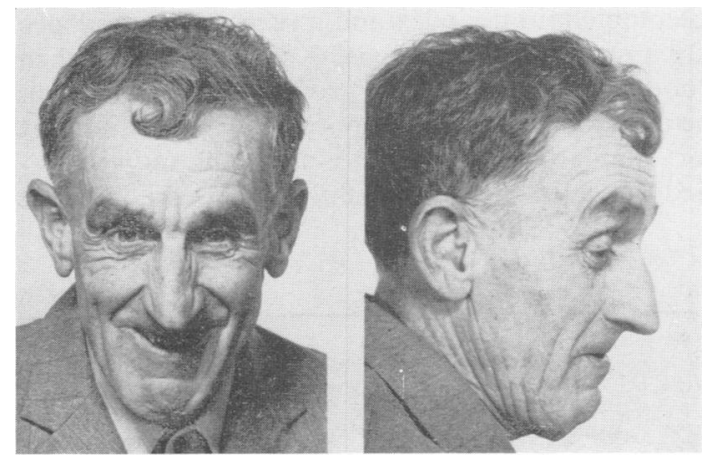

FIG 11 Patient $W W$.

when he would adopt a threatening attitude, gesticulate, and throw objects, shouting and screaming. He had heterochromia of his irises, fine, soft skin with café-au-lait patches, pubic hair of female distribution, kyphoscoliosis, broad digits, and clinodactyly of the fifth fingers. EEG showed low to moderate amplitude $6 \mathrm{c} / \mathrm{s}$ rhythmic activity from all areas with posterior theta activity outside the normal range.

FAMILY M

$E M$ (fig 12) had one mentally handicapped brother but no other family history is available. $\mathrm{He}$ is moody

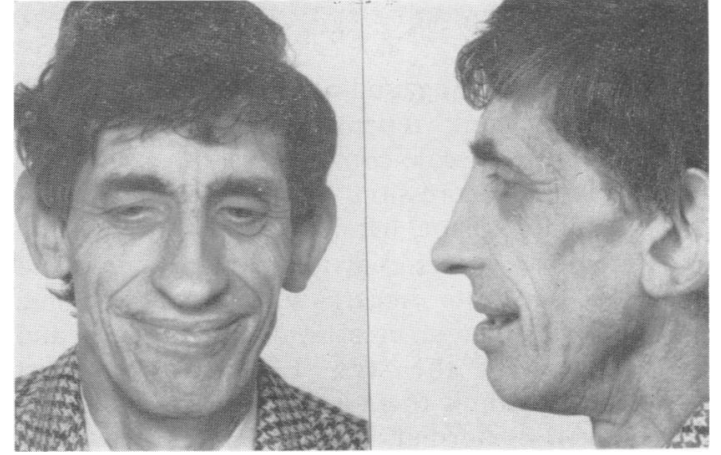

FIG 12 Patient EM.

and can be irritable, aggressive, and lazy, but will work at some simple tasks. His speech is poor with single words only and he is moderately deaf in both ears. The irises show heterochromia and the skin shows hyperpigmentation with a café-au-lait patch on the left buttock and small depigmented areas on the trunk. Skeletally there is kyphoscoliosis and lumbar lordosis, coxa vara, and large hands and feet with broad digits.

FAMILY R

A full pedigree could not be compiled on this family. The mother of probands ER, KR, and BR has low intelligence; she also has a daughter, unavailable for study, with an IQ of 51, who is GG's mother.

$E R$ is a female carrier of the fragile $\mathrm{X}$. She has an equable temperament and smiles and rocks. She does simple domestic tasks and has simple speech with repetition of phrases. The eyes show heterochromia and myopia. She has broad distal phalanges with clinodactyly of the fifth fingers, pes planus, bilateral varicose veins, normal female genitals and secondary sexual characteristics, papular irritative skin rash, and reticular pigmentation over the abdomen.

$K R$ is sociable and co-operative and works as a gardener. His speech is clear and he uses simple sentences. The eyes are bright blue with pterygium on the left, mongoloid slant, and ptosis. There is 
calcification of the left pinna, café-au-lait patches, dorsal kyphosis, clinodactyly of the fifth fingers, inguinal creases, varicose veins, and a right varicocele. EEG showed very low amplitude rhythms, occipital alpha activity, and bilateral delta and theta frequencies.

$B R$. This case was reported in detail as RubinsteinTaybi syndrome by Jancar. ${ }^{14}$ Subsequently he developed bilateral hydroceles, treated by radical surgery at the age of 30 .

$G G$ is sociable, smiling, and occupied in the gardens. Speech is constant, repetitive, perseverative, and echolalic. Reynell scale comprehension was 2 years 10 months and expression 4 years. He has brown eyes, mongoloid slant, left internal strabismus and severe myopia, pectus excavatum, large hands and feet, long spatulate fingers with some webbing, large big toes, inguinal creases, male body hair, and hypertrichosis of the legs. EEG showed short episodes of rhythmic theta activity at 4 to $7 \mathrm{c} / \mathrm{s}$, but was otherwise normal. Illinois test of psycholinguistic abilities was undertaken at the age of 21 . Overall psycholinguistic age was 3 years, auditory reception 3 years 5 months, auditory association 3 years 11 months, auditory memory less than 2 years, visual reception 3 years 7 months, visual association 4 years 4 months, visual closure 2 years 6 months, and manual expression 3 years 6 months. There was discrepancy between symbolic level and automatic level and he had very poor listening skills. Merrill
Palmer mental age was 3 years 6 months at the age of 21.

FAMILY N

Proband GN has one mentally handicapped brother, living with his parents, who have not yet agreed to further examination for the fragile $\mathrm{X}$ chromosome.

$G N$ is sociable and cheerful, with occasional episodes of agitation. Speech is rapid with slurred diction and sentences contain two concepts. He has facial asymmetry and macrostoma and the eyes show heterochromia, left ptosis, and right mongoloid slant. He has café-au-lait macules, male body hair, dorsal scoliosis, large hands (metacarpal index 8.8), and broad big toes.

\section{Cytogenetic investigations}

\section{BLOOD CULTURES}

During the early investigations, blood cultures were grown in medium TC 199 with $5 \%$ newborn calf serum. After experience with a variety of modifications (McCoy's medium plus FudR; TC 199 without serum; use of methotrexate) it was concluded that the best balance between achieving an acceptable mitotic index and a reasonable incidence of expression for the fragile $\mathrm{X}$ was obtained when blood cultures were simply grown in TC 199 without the addition of serum. More recently, it has become our standard procedure to add $100 \mathrm{mg} / \mathrm{l}$ of $\mathrm{L}$ methionine to the blood cultures. This practice was

TABLE 2 Cytogenetic results: incidence of fragile X chromosome.

\begin{tabular}{|c|c|c|c|c|c|c|c|}
\hline \multirow[t]{2}{*}{ Patient } & \multicolumn{3}{|l|}{ Blood } & \multicolumn{4}{|l|}{ Skin } \\
\hline & & & Culture conditions & Medium + & $F B S$ & Medium & $F B S+$ methionine \\
\hline $\begin{array}{l}\text { EA } \\
\text { BA } \\
\text { SP } \\
\text { AP }\end{array}$ & $\begin{array}{c}1 / 37 \\
6 / 60 \\
8 / 56 \\
\text { (1) } 0 / 135 \\
\\
\text { (2) } 0 / 85\end{array}$ & $\begin{array}{l}(2 \cdot 7 \%) \\
(10 \%) \\
(14 \cdot 3 \%)\end{array}$ & $\begin{array}{l}199, \text { no serum } \\
199, \text { no serum } \\
199, \text { no serum + M } \\
\text { McCoys + FUdR } \\
199, \text { no serum }+M / \\
199, \text { no serum }+M+ \\
199, \text { no serum } \\
199, \text { no serum + M }\end{array}$ & $\begin{array}{c}1 / 54 \\
11 / 161 \\
13 / 137\end{array}$ & $\begin{array}{l}(1.9 \%) \\
(6.8 \%) \\
(8.8 \%)\end{array}$ & $\begin{array}{c}5 / 60 \\
4 / 32 \\
16 / 135 \\
1 / 445\end{array}$ & $\begin{array}{l}(8 \cdot 3 \%) \\
(12 \cdot 3 \%) \\
(11 \cdot 9 \%)\end{array}$ \\
\hline $\begin{array}{l}\text { HH } \\
\text { IH } \\
\text { WH } \\
\text { EW } \\
\text { WW }\end{array}$ & $\begin{array}{l}6 / 12 \\
8 / 15 \\
6 / 15 \\
6 / 38 \\
4 / 30\end{array}$ & $\begin{array}{l}(50 \%) \\
(50 \%) \\
(40 \%) \\
(15 \cdot 8 \%) \\
(13 \cdot 3 \%)\end{array}$ & $\begin{array}{l}199, \text { no serum } \\
199, \text { no serum } \\
199, \text { no serum } \\
199+5 \% \text { NCS } \\
199+5 \% \text { NCS }\end{array}$ & $\begin{array}{l}5 / 78 \\
4 / 62 \\
4 / 53 \\
5 / 88 \\
\text { (1) } 7 / 126 \\
\text { (2) } 2 / 37\end{array}$ & $\begin{array}{l}(6.4 \%) \\
(6.5 \%) \\
(7.5 \%) \\
(5.7 \%) \\
(5.6 \%) \\
(5.4 \%)\end{array}$ & $\begin{array}{c}9 / 86 \\
5 / 25 \\
15 / 70 \\
20 / 171 \\
9 / 70 \\
6 / 54\end{array}$ & $\begin{array}{l}(10 \cdot 5 \%) \\
(20 \%) \\
(21 \cdot 4 \%) \\
(11 \cdot 7 \%) \\
(12.9 \%) \\
(11 \cdot 1 \%)\end{array}$ \\
\hline $\mathbf{E M}$ & $\begin{array}{l}\text { (1) } 11 / 35 \\
\\
\text { (2) }(8 / 30) \\
(8 / 30) \\
(8 / 30) \\
(8 / 30)\end{array}$ & $\begin{array}{l}(31 \cdot 4 \%) \\
(26 \%)\end{array}$ & $\begin{array}{l}\text { 199, no serum } \\
\text { (inc FUdR etc) }\end{array}$ & $\begin{array}{l}8 / 117 \\
7 / 99\end{array}$ & $\begin{array}{l}(6.8 \%) \\
(\mathrm{Na} \text { citrat } \\
(7.0 \%) \\
\left(\mathrm{H}_{2} \mathrm{O} \text { as }\right.\end{array}$ & $\begin{array}{l}23 / 135 \\
\text { potonic) } \\
7 / 84 \\
\text { ic) }\end{array}$ & $\begin{array}{l}(17 \%) \\
(8.3 \%)\end{array}$ \\
\hline $\begin{array}{l}\text { ER } \\
\text { KR } \\
\text { BR } \\
\text { GG } \\
\text { GN }\end{array}$ & $\begin{array}{r}16 / 34 \\
19 / 45 \\
4 / 72 \\
2 / 70 \\
17 / 30\end{array}$ & $\begin{array}{l}(47 \%) \\
(42.2 \%) \\
(5 \cdot 6 \%) \\
(2.9 \%) \\
(56.6 \%)\end{array}$ & $\begin{array}{l}199, \text { no serum } \\
199, \text { no serum } \\
199, \text { no serum } \\
199, \text { no serum } \\
199 \text {, no serum }\end{array}$ & $8 / 109$ & $(7 \cdot 3 \%)$ & $13 / 88$ & $(14 \cdot 7 \%)$ \\
\hline
\end{tabular}


adopted after the value of adding excess methionine to fibroblast cultures became apparent (see below), although the benefits of additional methionine in blood cultures have not been as clearly established. The culture conditions are included in table 2 , which shows the incidence of the fragile $\mathrm{X}$ chromosome in the patients under study. After locating metaphases with an apparent fragile $X$ on conventionally stained preparations, the chromosomes were destained and the identity of the fragile $\mathrm{X}$ confirmed by $\mathrm{G}$ banding (fig 13).

\section{FIBROBLAST CULTURES}

Much effort was devoted to identifying optimal conditions for demonstrating the fragile X chromosome preparations from fibroblast cultures as a prerequisite to any potential application of the technique to antenatal diagnosis on cultured amniotic fluid cells.

Fibroblasts were grown from primary explants in $25 \mathrm{~cm}^{2}$ plastic tissue culture flasks (NUNC) in TC 199 medium with $20 \%$ fetal bovine serum and $10 \%$ human $\mathrm{AB}$ serum and subcultured by trypsinisation as required. At the final subculture before harvesting, the concentration was reduced to $5 \%$ fetal bovine serum only. Following a report by
Howard Peebles ${ }^{18}$ that methionine is required for the expression of the fragile $\mathrm{X}$ in blood cultures, $100 \mathrm{mg} / \mathrm{l}$ of L-methionine were added to the fibroblast culture medium. The results are illustrated in table 2 which demonstrates a consistent and significant (two- to four-fold) increase in the incidence of the fragile site in the presence of excess methionine without any evidence of toxicity to the cultures. Experiments to assess the merits of growing and harvesting fibroblasts on coverslips, compared with harvesting a cell suspension after trypsinisation from flasks, showed that there was no significant difference in these techniques as far as demonstrating the fragile $\mathrm{X}$ chromosome was concerned. ${ }^{19}$ The results illustrated are derived from experiments in which cells were harvested in suspension, this being the standard technique in this laboratory.

Cultures were harvested 48 hours after final subculture, using $1 \%$ sodium citrate as a hypotonic agent and 3:1 methanol:acetic acid fixative. Experiments with alternative hypotonic agents suggested that the incidence of expression of the fragile site was usually lower when hypotonic agents other than sodium citrate were used; this is in agreement with the observations of Jacky and Dill. ${ }^{20}$

Use of this regimen has enabled the consistent

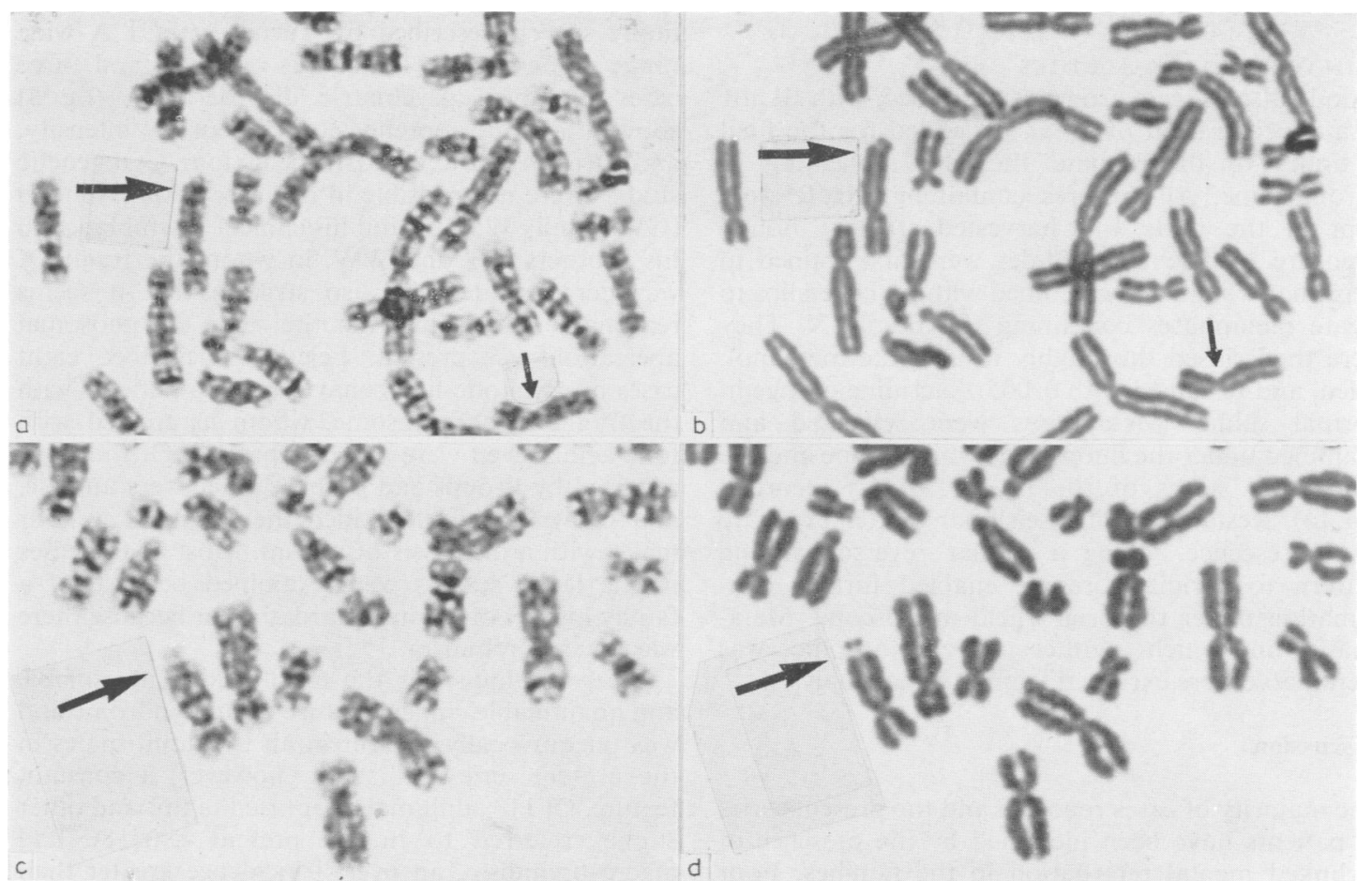

FIG 13 Identity of fragile $X$ confirmed by $G$ banding. 


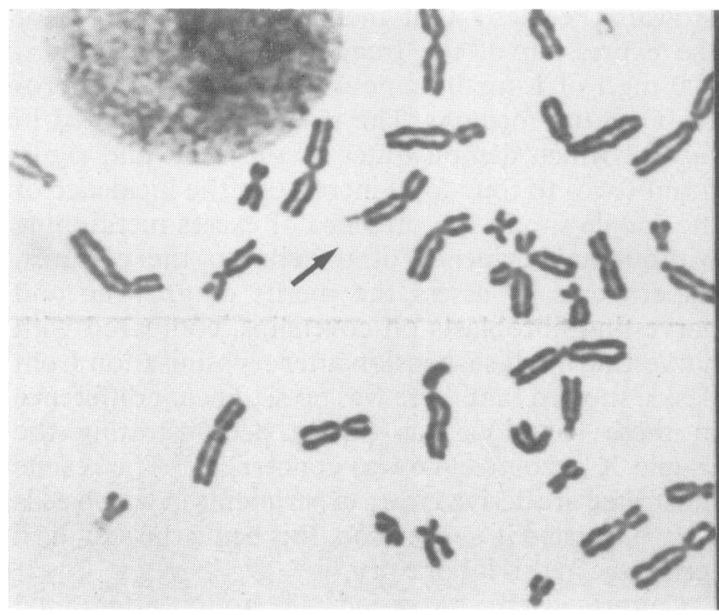

(a)

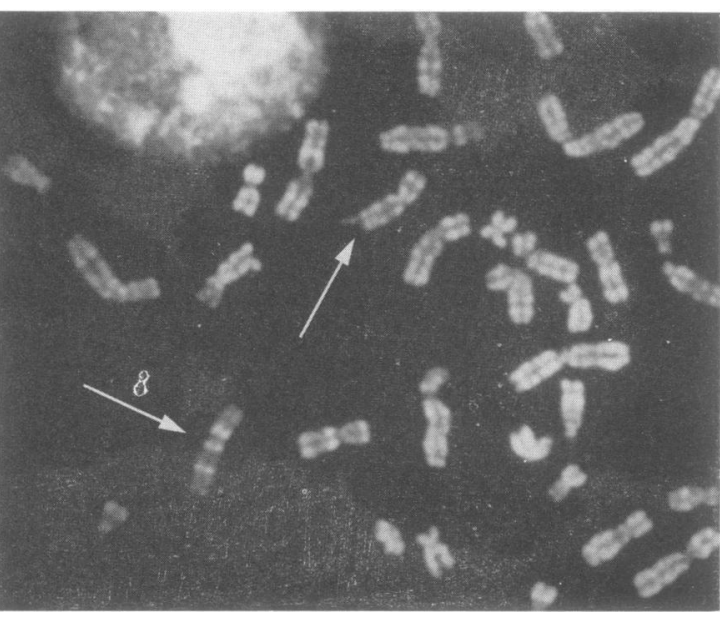

(b)

FIG 14 Fragile X chromosome (a) identified by Leishman's stain, and $(b)$ the same cell stained subs zquently with acridine orange to differentiate the early and late replicating $X$ chromosomes. In this cell the fragile $X$ is early replicating.

demonstration of the fragile $\mathrm{X}$ in all fibroblast cultures shown from known carriers of this chromosome aberration investigated in this laboratory. It has been applied successfully to cultures up to the sixth passage and in cultures retrieved from storage in liquid nitrogen.

\section{INACTIVATION STUDIES}

Blood cultures were grown as described, with BUdR at a concentration of $50 \mu \mathrm{g} / \mathrm{ml}$ added for the final 6 hours to differentiate the late replicating $X$ chromosome. All cultures containing BUdR were kept in the dark and harvested after $1 \frac{1}{2}$ hours' exposure to colchicine. Slides were first stained in Leishman's stain and examined without coverslips to locate metaphases containing the fragile X. They were then rinsed thoroughly in absolute methanol, dried, and restained with $0.005 \%$ acridine orange in normal saline. Metaphases were relocated and examined under the fluorescence microscope and the replication status of the fragile $X$ was recorded (fig 14). Restaining with Leishman's after exposure to fluorescence, giving a similar reverse banding pattern to acridine orange, enabled further confirmation under the bright field microscope. Metaphases in which neither $X$ chromosome was identifiable were excluded from the final analysis.

\section{Discussion}

The majority of cases reported and the present series of patients have been identified by the presence of $X$ linked mental retardation in the families. Four families reported have included mentally retarded females; only one, in whom the fragile $X$ was $\vec{\oplus}$ confirmed, was available for study. All the subjects are moderately or severely mentally retarded with no particular discrepancy between language and speech skills and other skills. There was abnormal speech in two cases but this could not be described as litany speech described by Turner et al. ${ }^{21} \mathrm{~A}$ wide range of personality traits was observed and three $\varnothing$ cases displayed psychiatric disorder. BA (fig 3) $\overrightarrow{\hat{0}}$ showed anxious apprehension of neurotic intensity, and AP (fig 4) showed autistic behaviour. Cytogenetic studies were not possible in our case with psychosis (GW, family W, II.5), but his clinical resemblance to his brothers EW and WW, in whom the fragile $X$ was demonstrated, was so striking that it seems reasonable to assume that the same chromosomal aberration was present. Lejeune ${ }^{16}$ described eight cases of psychotic-like behaviour in 16 patients with the fragile $\mathrm{X}$ chromosome, whom he treated with folic acid. Seven were much improved. Of the cases reported by Proops and Webb, ${ }^{22}$ three were autistic, and Brown et $a l^{23}$ identified the fragile $\mathrm{X}$ in four $N$ males with a diagnosis of autism. Most of the cases in the latter studies were examined because of a family history of mental retardation or because there was macro-orchidism.

Macro-orchidism is the most readily identifiable 0 and quantifiable clinical feature of the syndrome and was unequivocally present in all the adult males in the present series. It is not, however, a constant feature. Of 113 adult males reported in this and other studies referred to in the present text, 86 had macro-orchidism, an overall incidence greater than $75 \%{ }^{1824-28}$ More general surveys of testicular 
volumes of men with severe mental deficiency have revealed only a small incidence. Rundle and Sylvester ${ }^{17}$ measured the testicular volumes of 265 hospital residents and found nine cases over the age of 15 with volumes in excess of 2 SD above the mean $(3.2 \%)$, and Cantu et al $^{29}$ reviewed 84 male inpatients and found three with testicular hyperplasia (3.6\%). Cantu et $a l^{29}$ reported the recognition of macroorchidism at birth in their familial cases but it is less frequently recorded in children with the fragile $X$ than in adults. If the benefits of folic acid treatment as reported by Lejeune ${ }^{16}$ are confirmed, then it is important that the diagnosis is made early, particularly in singleton cases presenting with retarded development.

The characteristic facial appearance of our patients has been shown in many other published photographs. Regular phenotypic features are high forehead, large simple ears, broad nose, hypoplasia of the maxilla, and prominent large mandible. In addition, eight patients showed a wide mouth and seven had facial asymmetry. These facial features have since been found to be sufficiently typical to enable the clinical identification of a number of individual adult cases with the syndrome in the absence of any family history.

It is interesting to note that in AP the resemblance to his retarded uncles was recognised by some family members at an early age although denied by his parents until he was 3 years old. When permission was given for chromosome studies at 4 years of age, two separate investigations on blood culture failed to reveal the presence of the fragile $\mathrm{X}$ chromosome although this was clearly demonstrated in the heterozygous mother. The fragile $\mathrm{X}$ was ultimately identified in fibroblast cultures grown according to the schedule described, albeit in only a single cell with certainty. We have experienced a similar phenomenon in another retarded male, not included in the present report, in whom the fragile $X$ was found in $13 \%$ of cells in a fibroblast culture, but could not be demonstrated in repeated blood cultures. This observation suggests that fibroblast cultures should be employed when there is clinical suspicion of the fragile $\mathrm{X}$ syndrome but no evidence of it in blood cultures. Searching for fragile sites on $\mathrm{X}$ chromosomes involves extensive screening if cases with a low incidence of expression are to be identified, and it is not feasible as a routine procedure for unselected cases in most diagnostic cytogenetics laboratories with a heavy workload. It is important, therefore, that the clinician alerts the laboratory to any suspicion that a fragile $X$ may be involved, so that the necessary special culture techniques may be employed. In this respect, particular attention should be paid to the facial features, testicular size, skin pigmentary changes, inguinal creases, and skeletal anomalies in the examination of children with nonspecific retardation, although it must be accepted that some cases may not show any of the features described.

Herbst and Miller ${ }^{4}$ suggest that the frequency of the fragile $X$ chromosome may be 0.9 per 1000 male births. Males of normal intelligence with the fragile $X$ have been reported ${ }^{30} 31$ and transmission of mental retardation through normal males has been demonstrated in the pedigrees studied by Webb et $a l^{31}$ and Martin and Bell. ${ }^{6}$ The incidence of the anomaly and the frequency with which it is associated with mental retardation, either in the individual or in the family, remain to be more clearly delineated.

Harvey et $a l^{10}$ stated that the risk of a carrier female having a retarded son was greater than $50 \%$. In our pedigrees 16 of 27 sons born to obligate carriers were mentally retarded.

Detailed cytogenetic studies were possible on only two heterozygous females in the families reported here. The incidence of the fragile $X$ was higher in both blood and fibroblast cultures (approximately $47 \%$ and $15 \%$ respectively) in ER, who was severely mentally retarded, than in SP (approximately $14 \%$ and $11 \%$ ), who had normal intelligence. Of greater interest, however, and possibly more significant, were the results of $X$ inactivation studies (table 3 ) which demonstrated that the fragile $X$ was genetically active in a conspicuously greater preponderance of cells $(74 \%)$ in the mentally retarded carrier while the reverse situation occurred, to virtually the same

TABLE 3 Replication status of the fragile X chromosome in three heterozygotes for fra $(X)(q 27)$.

\begin{tabular}{|c|c|c|c|c|c|c|}
\hline \multirow[t]{3}{*}{ Patient } & \multirow[t]{3}{*}{ Culture regimen } & \multicolumn{5}{|c|}{ No of cells examined } \\
\hline & & \multicolumn{4}{|c|}{ Fragile $X$ replication status } & \multirow[b]{2}{*}{ Total } \\
\hline & & Early & Late. & Both & Unresolved & \\
\hline $\begin{array}{l}\text { ER Mentally } \\
\text { retarded, age } 48\end{array}$ & TC $199+$ methionine & $23(74 \%)$ & $5(16 \%)$ & 0 & 3 & 31 \\
\hline SP Family A (III.7) & TC $199+$ methionine & 5 & 18 & 1 & 2 & 26 \\
\hline \multirow[t]{2}{*}{$\begin{array}{l}\text { Normal intelligence, } \\
\text { age } 33\end{array}$} & $\begin{array}{l}\text { TC } 199+\text { methionine } \\
+ \text { FUdR }\end{array}$ & 2 & 7 & 0 & $\mathbf{0}$ & 9 \\
\hline & Combined & $7(20 \%)$ & $25(72 \%)$ & 1 & 2 & 35 \\
\hline
\end{tabular}


extent $(72 \%)$, in the carrier with normal intelligence. More information on the relationship between mental capacity and $X$ inactivation patterns in heterozygous females may prove valuable in the prediction of abnormality in antenatally identified females and, although many more data are required before meaningful speculation can be made, our observations on these two cases are interesting in this respect.

We are grateful to Dr Diana Gordon for clinical details of AP, to Dr D James for permission to include details of families $R$ and $N$, to Dr J Jancar and Dr Yvonne Wiley for their helpful collaboration in this study, and to Dr Singh for information included in fig 9.

\section{References}

1 Penrose LS. A clinical and genetic study of 1280 cases of mental defect (the Colchester survey). MRC Special Report Series No 229. London: Medical Research Council, 1938.

${ }^{2}$ Lehrke RG. X-linked mental retardation and verbal disability. New York: Intercontinental Medical Book Corp, 1974

3 Turner G, Turner B. X-linked mental retardation. J Med Genet 1974;11:109-13.

${ }^{4}$ Herbst DS, Miller JR. Non-specific X-linked mental retardation. 11: the frequency in British Columbia. Am J Med Genet 1980;7:461-9.

5 Berry C. X-linked mental retardation. Arch Dis Child $1981 ; 56: 410-1$.

6 Martin JP, Bell J. A pedigree of mental defect showing sex-linkage. $J$ Neurol 1943; VI New Series 3 and 4: 154.

7 Renpenning H, Gerrard JW, Zaleski WA, Tabata T. Familial sex-linked mental retardation. Can Med Assoc J $1962 ; 87: 954-6$.

8 Turner G, Eastman C, Casey J, McLeay A, Procopis P, Turner B. X-linked mental retardation associated with macro-orchidism. J Med Genet 1975;12:367-71.

9 Lubs HA. A marker X chromosome. Am J Hum Genet $1969 ; 21: 231-44$.

10 Harvey J, Judge C, Wiener S. Familial X-linked mental retardation with an $\mathrm{X}$ chromosome abnormality. $\mathrm{J}$ Med Genet 1977;14:46-50.

11 Sutherland GR. Fragile sites on human chromosomes, demonstration of their dependence on the type of tissue culture medium. Science 1977;197:265-6.

12 Richards BW, Sylvester PE, Brooker C. Fragile X-linked mental retardation: the Martin-Bell syndrome. J Ment Defic Res $1981 ; 25: 253$.

13 Fox P, Fox D, Gerrard JW. X-linked mental retardation: Renpenning revisited. Am J Med Genet 1980;7:491-5.
14 Jancar J. Rubenstein-Taybi syndrome. J Ment Defic Res $1965 ; 9: 265-70$.

15 Jancar J. Familial mental handicap. Bristol Med Chir J $1983 ; 98: 23-7$.

16 Lejeune $J$. Is the fragile $X$ syndrome amenable to treatment? Lancet $1982 ; \mathrm{i}: 273-4$.

17 Rundle AT, Sylvester PE. Measurement of testicular volume. Arch Dis Child 1962;37:514-7.

18 Howard-Peebles PM.Fragile sites in human chromosomes 11: demonstration of the fragile site Xq27 in carriers of X-linked mental retardation. Am J Med Genet 1980;7: 497-501.

19 Gardner AP, Howell RT, McDermott A. Fragile X chromosome: consistent demonstration of fragile site in fibroblast cultures. Lancet $1982 ; \mathbf{i}: 101$.

20 Jacky PB, Dill FJ. Expression in fibroblast culture of the satellited-X chromosome associated with familial sexlinked mental retardation. Hum Genet 1980;53:267-9.

21 Turner G, Danial A, Frost M. X-linked mental retardation, macro-orchidism and the $\mathrm{X}(\mathrm{q} 27)$ fragile site. J Pediatr 1980;96:837-41.

22 Proops R, Webb T. The 'fragile' $X$ chromosome in the Martin-Bell-Renpenning syndrome and in males with other forms of familial mental retardation. $J$ Med Genet $1981 ; 18: 366-73$.

23 Brown WT, Friedman E, Jenkins EC, et al. Association of fragile X syndrome with autism. Lancet $1982 ; \mathbf{i}: 100$.

24 Turner G, Opitz JM. X-linked mental retardation. Am J Med Genet 1980;7:407-15.

25 Martin RH, Lin CC, Mathies BJ, Lowry RB. X-linked mental retardation with macro-orchidism and marker $\mathrm{X}$ chromosomes. Am J Med Genet 1980;7:433-41.

26 Jacobs PA, Glover TW, Mayer M, et al. X-linked mental retardation: a study of 7 families. Am J Med Genet $1980 ; 7: 471-89$.

27 Jennings M, Hall JG, Hoehn H. Significance of phenotypic and chromosomal abnormalities in X-linked mental retardation (Martin-Bell or Renpenning syndrome). Am J Med Genet 1980;7:417-32.

${ }^{28}$ Gustavson $\mathrm{KH}$, Holmgren $\mathrm{G}$, Blomquist HK, et al. Familial X-linked mental retardation and fragile $X$ chromosome in two Swedish families. Clin Genet 1981 19:101-10.

${ }^{29}$ Cantu JM, Scaglia HE, Median M, et al. Inherited congenital normo-functional testicular hyperplasia and mental deficiency. Hum Genet 1976;33:23-33.

30 Daker MG, Chiadic P, Fear CN, Berry AC. Fragile X in a normal male. A cautionary tale. Lancet $1981 ; \mathbf{i}: 780$.

31 Webb GC, Rogers JC, Pitt DB, Halliday J, Theobald T. Transmission of fragile (X)(q27) site from a male. Lancet 1981 ;ii:1231-2.

Correspondence and requests for reprints to Dr A McDermott, South Western Regional Cytogenetics Centre, Department of Pathology, Southmead Hospital, Westbury-on-Trym, Bristol BS10 5NB. 